\title{
Exercise Training Program and Telenursing Effects on Depression and Fatigue Level in B-Thalathemia Major Children
}

\author{
Fawzia EI Sayed Ali Abusaad ${ }^{1}$, Mohamed Mahmoud Sarhan ${ }^{2}$ \\ ${ }^{1}$ Pediatric Nursing Department, Faculty of Nursing, Mansoura University, Mansoura City, Egypt \\ ${ }^{2}$ Pediatric Medicine Department, Faculty of Medicine, Mansoura University, Mansoura City, Egypt
}

Email address:

fawziaabusaad2013@gmail.com (F. E1 S. A. Abusaad)

\section{To cite this article:}

Fawzia El Sayed Ali Abusaad, Mohamed Mahmoud Sarhan. Exercise Training Program and Telenursing Effects on Depression and Fatigue Level in B- Thalathemia Major Children. American Journal of Nursing Science. Vol. 5, No. 5, 2016, pp. 191-200. doi: 10.11648/j.ajns.20160505.14

Received: August 28, 2016; Accepted: September 5, 2016; Published: October 11, 2016

\begin{abstract}
Background: B-Thalassemia major considered as a serious life-threatening disease for pediatric population that causes substantial disruption in all aspects of child life. With advanced, effective management and even cure of thalassemia become possible, attention is drawn to the evaluation of depression and fatigue that accompany suffering children. Aims: investigate the effects of exercise training program combined with 3 months nurse -telephone follow up calls on depression and fatigue level in children with B-thalassemia major. Design and Method: A quasi experimental study was conducted on 60 thalassemic children who selected randomly after fulfilling the criteria of selection at hematology outpatient clinic of mansoura university children's hospital using three tools of data collection; structured interview questionnaire, depression inventory and fatigue scale. Exercise training either aerobic and anaerobic types was specific for the study subjects and they were followed by telephone follow up calls for three months by the researchers. Results: All thalassemic children suffer from depression with different categories and $95 \%$ of them suffer from fatigue before intervention. With telenursing follow up calls the total score of depression and fatigue were decreased after one month of exercise performance than before and continuously decreased after three months of exercise performance. Conclusion: The exercise training program combined by follow up calls was effective in decreasing depression and fatigue among thalassemic children after one and three months of intervention. Recommendation: It is suggested for performing and training the regular exercises as a routine care for those pediatric population.
\end{abstract}

Keywords: Exercise Program, Tele nursing, Depression, Fatigue, Major thalassemia, Children

\section{Introduction}

Thalassemia considered as the commonest of all single gene disorders, it constitute the world's most widespread genetic diseases. Beta Thalassemia comprises a heterogenous group of hemoglobin disorders characterized by a reduction or a complete absence of b-globin gene expression that results from inheritance of an autosomal recessive gene (Shawkyand Kamal, 2012). The total annual incidence of symptomatic individuals is estimated at 1 in 100,000 throughout the world. In Egypt, homozygous beta Thalassemia is a major public health problem where over 1-5 million newborns are expected to be affected with this disorder, and it is considered the most common chronic hemolytic anemia in $85.1 \%$ of cases. In Egypt A high rate of carriers has been reported and reaching up to $9-10 \%$ (ElShanshory et al, 2014). The total follow up cases of Thalassemia children that attend the hospital for blood transfusion or chelation therapy is estimated to be around 400 child as reported by statistical records of Mansoura university children's hospital 2016.

Thalassemias is a serious health problem not only for the children and their families but also for the community Health System because of the cost of treatment involving regular transfusions, iron chelation, frequent hospitalization and general medical follow up (Kargar Najafi et al, 2011). The consequences of Thalassemias on physical health can lead to physical deformity, growth retardation, and delayed puberty. 
Its impact on physical appearance, bone deformities and short stature contributes to a poor self-image. The common complications among those patients are heart failure, cardiac arrhythmia, liver disease, endocrine complications, and infections (Al Ebrahimy, Al Jebory and jehad, 2015). Although cure of Thalassemias become possible, attention is given to evaluate the associated psychiatric disorders such as depression that frequently accompany these chronic disease (Koutelekos and Haliasos, 2013).

Depression is a common psychological problems that exerts a negative influence on child life, with a prevalence of $2 \%$ $3 \%$. The causes of depression in children and adolescents is not well understood compared to adults, however it is considered as a result of interaction between stressful events of chronic illness and associated problems such as family-related problems, economic difficulties, social factors as peer group or school achievement (Bould et al, 2013). A study made by Bakr et al (2007) reported that, psychiatric disorders in all the studied pediatric patients at El-Mansoura University Children's Hospital were adjustment disorders, neurocognitive disorders, anxiety, elimination disorders and depression. Another study (Hashad et al, 2015) represent $91.9 \%$ of children had depression that categorized into mild depression in $28.4 \%$ of children, more than one third of them had moderate depression and $24.3 \%$ of them had severe depression.

Fatigue is a subjective feeling and diffuse experience that involves physical, cognitive and psychological aspects of child life. It manifested in weakness, lack of energy and feeling of exhaustion (Nunes et al, 2014). Fatigue affects not only day life but also disturbed daily self care activities, emotional status, and therefore the quality of life. There is a positive association between feeling of fatigue and children activity level, As a result of diminished activity, the individual's strength reduced, leading to anxiety and depression. Therefore, the various treatment strategies that focused on exercise, psychosocial support, stress management, nutrition and sleep regulation must be effective to handle fatigue (Mohamed, 2014).

Exercise intolerance and fatigue are common complains in Thalathemia major children that result from the low capacity of oxygen transportation and decreased extraction of oxygen from peripheral skeletal musculature. Most studies have attributed these findings to a combination of anemia and iron-mediated cardiotoxicity (Sohn et al, 2012). It has been shown that exercise in the form of aerobic and anaerobic natureis important for daily activities performed by children. Exercise performance can be enhanced through participation in structured exercise programs that need less oxygen consumption, did not interfere with their hemodynamic, and performed easily can improve their anaerobic and aerobic fitness (Marinov et al, 2008).

Non-pharmacological approaches aim mostly at relieving pain, decreasing stiffness, and avoiding pain recurrence. It involves physiotherapy, physical therapy and exercise that help in preventing malalignment and improve function. Beta Thalassemia children are less physically active compared to healthy peers. This lower activity level associated with a higher prevalence of psychological and emotional distress. There is strong evidence that physical activity is important for children's psychological well-being (Brussel et al, 2007). Performing regular structured exercise for those children can be beneficial in fighting depression compared to antidepressant medications as strength training may cause a biochemical response in children brain that plays a role in improving their moods and mental health. Also exercise helps reverse the effects of bone loss and reduces the risk of broken bones and osteoporosis (Rezaei et al, 2015).

Pediatric nurse are trained to treat children with Thalassemia, meet their specific needs and counsel their family members about various treatment modalities and prevention ofserious complications under the supervision of a hematologist. Nowadays nurses use telenursing for all processes of nursing involves assessment, planning, intervention, and evaluation of the results of their nursing cares (Health Resources and Services Administration, 2007). Telenursing includes contact between the medical health care worker, as doctors, nurses and allied health professionals and the patients by the use of telephone, radio, television, video and internet. In telenursing, children and their caregivers receive telephone calls from a trained nurse at a periodical basis for follow up in which they receives continuing education and monitors their compliance with treatment modalities. They also, skillful in revealing hidden emotions, negative feeling of fatigue and internal conflicts that interfere with children sense of adaptation to the disease (Hockenberry and Wilson, 2013).

Telenursing services aim to establish a relationship with the caller, identify the concern, assess the condition, solve problems in collaboration with the caller, and select appropriate solutions (Wagner and Bear, 2009). A literature search found only two pediatric studies that evaluated this type of telephone service. Gischler et al (2008) evaluated the frequency and the nature of the calls made by parents of children born with severe anatomical congenital anomalies to a 24-hour telephone help line that provides easy access to medical information and offers supportive care to parents at relatively low cost. This nurse-led telephone intervention proved to be safe and efficient when back-up by a pediatric physician was provided. Another study made by Letourneau et al (2003) described the use of a TN line in a pediatric neurology clinic that concerned with problems related to epilepsy and nurses were able to solve half of the problems without requiring further medical intervention. Although these two studies are descriptive in nature, they demonstrate that a TN line may indeed assist in the provision of care, support and follow up children with chronic disease. A widespread utilization of home phone or mobile among individuals, telephone focused system particularly (telephone follow -up call), would be an efficient technique for transporting educational services for thalassemic children to their homes that consequently promote nurse- patient relationship, safe time and reduce the cost of treatment (Ghazanfari, Arab, ForouziandPouraboli,2010). 


\subsection{Significance of the Study}

Thalassemia major is a serious health problem in Egypt in which children are in need of regular blood transfusions from a very young age to survive. They also need to receive iron chelation therapy to remove excess iron from their bodies, which imposes serious clinical and psychological depressive symptoms challenges (Elalfy et al,2014). In recent years, many studies stressed on nonmedical treatments to cure depression in children with chronic diseases instead of drug therapy. Exercise or physical activity as a nonpharmacological care are suggested to treat or help to cure major depression (Rezaei et al, 2015). Communication follow-up for thalassemic children is critical for the physical and psychological wellbeing of both child and family. To the best of our knowledge this area of training children specific types of exercise and follow up their regularity and satisfaction at home through phone call to handle depression and fatigue have never been studied before in pediatric population suffering from Thalassemia.

\subsection{Aim of the Study}

To investigate the exercise training program and telenursing effects on depression and fatigue level in children with B Thalathemia Major.

\subsection{Research Hypothesis}

Thalassemic children's who receive exercise training program combined with telephone follow up calls for three months will demonstrate a reduction in depression and fatigue levels.

\section{Subjects and Methods}

\subsection{Study Design}

A quasi experimental research design was used to conduct the study.

\subsection{Study Setting}

The study was conducted at Hematology outpatient clinic of El-Mansoura University Children's Hospital

\subsection{Study Subject}

A sample of 60 children suffering from B- Thalassemias major and attended the Hematology outpatient clinic for blood transfusion and chelation therapy and willing to participate in the study were selected by simple randomization after fulfilling the inclusion criteria:

- $\quad$ Age from10-17years.

- Both sexes.

- Free from history of heart failure or on cardiac medications at the time of the study.

- Free from hemodynamic instability or neurological or orthopedic (bone surgery, under correction surgery) diseases that limited exercise performance.

- All participants during this study had a mobile or home phone.

\subsection{Tools of Data Collection}

Three tools were used to collect data:

\subsubsection{A semi - Structured Interview Questionnaire}

That was developed by the researchers after reviewing the related literature. This tool was written in an Arabic language to suit the level of children understanding. It was composed of the following parts:

A- Sociodemographic data of children, which includes: age, sex, level of education, birth order, residence and socioeconomic status that assessed by using socioeconomic scale for health research in Egypt (El-Gilany et al, 2012). This scale include 7 domains with a total score of 84 and classified the socioeconomic level into high level with score range from $64-84$, middle $43-63$, low $22-42$ and very low range from 0-21.

$B$ - Children's clinical data, which includes: duration of disease or treatment, regularity of blood transfusion, number of blood transfusion per month, iron chelation compliance and family history of Thalassemia. Additional two questions were asked about regular exercise training and satisfaction of children with exercise performance.

\subsubsection{Depression Inventory Scale}

The children's depression inventory adopted from Kovacs, 1985 and translated to Arabic version by Garieb, 2012, which is a27 -multiple - choice self - report composed of items relating to symptoms of depression (such as social isolation, feeling of sadness, fatigue, low energy, loss of appetite and lack of safety,....Each item consists of three statements from which the child are instructed to choose the one statement that best describes them over the last two weeks. Each question is designed to assess specific symptoms of depression and the three choices range from mild or limited symptomatology to severe or maladaptive symptomatology.

Scoring system: Each item scored0,1and2with score of2representing the most severe choice. The Children's Depression Inventory was used with total score (54) marks, distributed for measuring the severity of depression as follows:

- Non of depression with score 14 marks.

- Mild depression with score range from 15 to 22 marks.

- Moderate depression with score range from 23 to 29 marks.

- Severe depression with score range from 30 to 54 marks.

\subsubsection{Fatigue Scale}

Adopted from Hinds et al., 2007, and translated to arabic by the researchers. This self-reporting 14 items that describe the fatigue intensity during the previous week in children using a five-point Likert scale.

Scoring system: score (1) given to no fatigue at all, score 
(2) for little fatigue, score (3) for half of time, score (4) for to some extend and score (5) for all the time, with total score (70) marks. The classification of the fatigue intensity ranges from:

- Non fatigue with score 14

- Mild fatigue with score range from 15 to 34

- Moderate fatigue with score range from 35 to 54

- Severe fatigue with score range from 55 to 70

\subsection{Field of Work}

Conceptual framework: The telenursing intervention is based on Cox's Interaction Model of Client Health Behavior (Cox,2003). This model offers support in determining the optimal way for a nurse to interrelate with a patient to reach positive health outcomes. The TN intervention is designed to ensure continuity of care for children and their families through a telephone service providing nursing advice to meet children's needs for: A - health information; through providing information about the child's health condition and explain treatments, medication, tests and the overall situation; the clarity of the information given is an important factor in satisfaction (Moscato et al 2007). B- Affective support: through giving children and their parents time to speak and will listen attentively to their concerns which is a predictor of satisfaction. C-Help in decision-making :The TN nurse will facilitate parents' involvement in making decisions by informing them of how their child's care is progressing and presenting them with the different options that are likely to suit their needs and address their concerns (Wahlberg, Cedersund and Wredling (2002) \& Beaulieu and Humphreys, 2008).

\subsection{Ethical Consideration}

A permission to conduct the study was obtained from authorized person in hematology outpatient clinic at Mansoura university children's hospital. The main study was conducted from February to July 2016.

Verbal consent was obtained from each child and their mothers for participation in the study after explaining the aim of the study. Anonymity, privacy, rights, safety of participants was fully assured from the start of the study and their right's to withdraw at any time with confidentiality of their data.

\subsection{Validity and Reliability of Tools}

The tools were tested for its content validity by 5 experts in pediatric and psychiatric nursing who revised the questions for clarity, relevancy, applicability, comprehensiveness, understanding and ease for implementation; according to their opinions minor modifications were applied. Alpha correlation coefficient was computed for the determination of the internal consistency reliability which was $\alpha=.79$ for children's depression inventory and $\alpha=0.87$ for fatigue scale.

\subsection{Pilot Study}

A pilot study was conducted on 10 children with Thalassemia major in order to test the applicability and relevance of the study tool and test clarity of the designed questionnaire as well as to estimate the time needed to answer them, those children were excluded from the study sample

\subsection{Exercise Training Program}

The exercise program consisted of endurance worming up, stretching, and relaxation exercises. These exercises were self administered performed two times weekly for $30-35 \mathrm{~min}$ and given as a home program aimed at promoting good health and alleviate depression and fatigue. The program was designed through consulting expertise in health science field, faculty of physical education. Safety of the exercise program for B Thalassemia major children was approved by the mentioned specialists that includes:

- Endurance exercises for joint warming include walking in place and going up and down a step or run in place. Alternate hip and knee flexion and extension exercise in a rhythmic and specific pace was conducted in 5-10 times for $5 \mathrm{~min}$.

- Dynamic or static stretching exercises were conducted to strengthen the upper, lower extremities, and trunk muscles. The exercises were administered for $10 \mathrm{~min}$ at the prolonged position of the muscles, with breaks for $10-15 \mathrm{sec}$.

- Resistance exercise training for $10 \mathrm{~min}$ : It was individually tolerated and applied for quadriceps and hamstrings in the form of weight resistance (sand bags from 2 to $6 \mathrm{~kg}$ ). Initially, a small weight was used and children performed sets of repetitions starting at 3 sets of 10 repetitions and progressed to 3 sets of 15 repetitions with 1 min rest period in between until the amount of weight lifted was no longer challenging.

- Cool down using relaxation positions, breathing control, and relaxation methods were implemented for the children. These methods were used for teaching children the difference between contraction and relaxation, which provided a state of relaxation for 5-10 min. The amount of training pressure was gradually increased from the second week onward, the number of repeats depended on the pressure of the activities during the training program.

- Each child with his or her mother were interviewed individually with adequate explanation and their demographic and clinical data was collected, baseline data about their depression and fatigue level (pretest) were assessed.

- The studied children was given the content of the exercise program on 2 interactive sessions during blood transfusion and chelation therapy administration. The session was conducted for 2 hour started from 11 a.m. to 1 p.m. Power point presentation and video were used followed by group discussion. In given poster, the type of each exercise and rest between them had been written. The exercise plan was done two times a week for twelve weeks at home, and every session has taken about 30-35 minutes. Children were instructed to immediately stop exercising if they felt pain, fainting or shortness of breath. 
- The studied children followed up for sixteen calls by the researcher with help of master nurse working in hospital. Telephone call follows up (in first month, two telephone calls every week and 1 telephone call every one week for the following two months). Basically, children were followed up for three month. Every nurse telephone call, children were asked about the regularity in performing trained exercise and detected health Problems. Once a health problem was discovered, children and their caregiver were advised regarding it and it was recorded to be followed in the next communication. All phone calls were recorded on phone call Form. Problems determined throughout phone calls, suggested solution, next interview dates, issues and evaluations that would be described at the subsequent interview were recorded to the same form.

- The studied children were reassessed after one month (post- test) for their depression and fatigue level using the same format, discussing any problems in applying exercise, it's possible solutions. Children regularity and satisfaction in performing exercise.

- After three month the follow up assessment (follow post-test) was done on studied children again to assess depression and fatigue levels. As well as asking about regularity and their satisfaction with the exercise program performance.

\subsection{Statistical Analysis}

Collected data were coded, computed and statistically analyzed using SPSS software program (statistical Package of Social Sciences) version 20.0. Qualitative categorical variables were presented as frequency and percentage while quantitative continuous variables were presented as mean \pm Sd. Chi Square test was used to find relations between categorical variables. Independent and paired t test was used to compare quantitative continuous variables in two groups. Statistical significant level was considered at $\mathrm{P} \leq 0.05$.

\subsection{Limitations}

Some limitations of the present study are the relatively small sample size from same place. Multi-center studies weren't included. No long period of follow-up because of financial burden and limited references available in pediatric population.

\section{Results}

Table 1. Frequency distribution of study sample according to their Sociodemographic characteristics and medical history $(N=60)$.

\begin{tabular}{lll}
\hline Items & $\mathbf{N}(\mathbf{6 0})$ & $\mathbf{\%}$ \\
\hline Age: $10-<15$ years & 38 & 63.3 \\
15-17years & 22 & 36.7 \\
Mean \pm SD13.7 \pm 2.1 & & \\
Sex: Male & 27 & 45 \\
Female & 33 & 55 \\
Residence: Rural & 49 & 81.7 \\
$\quad$ Urban & 11 & 18.3 \\
\hline
\end{tabular}

\begin{tabular}{|c|c|c|}
\hline Items & $\mathbf{N}(60)$ & $\%$ \\
\hline Birth order: First & 15 & 16.7 \\
\hline In between & 42 & 70 \\
\hline Last & 8 & 13.3 \\
\hline \multicolumn{3}{|l|}{ Educational Level: } \\
\hline Primary & 13 & 21.7 \\
\hline Preparatory & 28 & 46.7 \\
\hline secondary & 19 & 31.6 \\
\hline \multicolumn{3}{|l|}{ Socioeconomic Level: } \\
\hline Moderate & 15 & 25 \\
\hline Low & 45 & 75 \\
\hline Disease duration: & \multirow{2}{*}{\multicolumn{2}{|c|}{$12.1 \pm 3.4$}} \\
\hline Mean \pm SD & & \\
\hline \multicolumn{3}{|l|}{ Family history of disease: } \\
\hline Positive & 44 & 73.3 \\
\hline Negative & 17 & 26.7 \\
\hline \multicolumn{3}{|c|}{ Blood transfusion regularity $\mid$ month } \\
\hline Regular & 51 & 85 \\
\hline Irregular & 9 & 15 \\
\hline \multicolumn{3}{|l|}{ Chaletion therapy: } \\
\hline Single & 48 & 80 \\
\hline Compound & 12 & 20 \\
\hline
\end{tabular}

It is clear from table (1) that most of studied children thalassemic children $(63.3 \%)$ their age were from 10 to less than 15 years and $36.7 \%$ of them their age were from 15 to 18 years with the age of $13.7+2.1$. Also more than half of them $(55 \%)$ were female and $81.7 \%$ of them were from rural areas. As regard birth order, $70 \%$ of studied children were in between and almost half $(46.7 \%)$ were in preparatory school as well as three quarter of children (75\%) have low socioeconomic level. According to children's medical history, It is evident that all studied children suffered from Thalassemia since 6 month with the mean age of 12.1 $\pm 3-4$ years of disease duration. As regard family history of the disease almost three quarter of children (73.3\%) have positive family history, and majority of children $(85 \%)$ on regular blood transfusion monthly, as well as $80 \%$ on single intravenous Chaletion therapy while only $20 \%$ on compound (both oral and intravenous) Chaletion therapy.

\section{Side effects of treatment}

\section{(blood transfusion \& chelation therapy)}

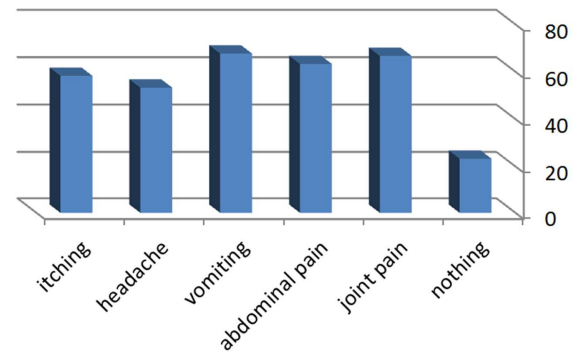

*more than one item was selected.

Figure 1. Represent side effects of treatment, about one quarter of children (23.3\%) have no side effects while most of children (67.7\%) had vomiting, $66.7 \%$ had joint pain, 63.3 had abdominal pain, 58.3\% had itching and $53.3 \%$ had headache respectively. 
Table 2. Total score of depression and fatigue among B-Thalassemia Major children before, after one month and after three month of exercise performance with telenursing follow up calls.

\begin{tabular}{|c|c|c|c|}
\hline \multirow{2}{*}{ Items } & Before exercise performance & After one month of exercise performance & After three month of exercise performance \\
\hline & Mean \pm SD & Mean \pm SD & Mean \pm SD \\
\hline Depression & $24.7 \pm 3.8$ & $19.2 \pm 4.6$ & $15.3 \pm 6.04$ \\
\hline Paired t-test & $\mathrm{T}_{1} 15.32, \mathrm{p}=.000$ & $\mathrm{~T}_{3} 13.502, \mathrm{p}=.000$ & $\mathrm{~T}_{2} 17.84, \mathrm{p}=.000$ \\
\hline Fatigue & $57.2 \pm 6.4$ & $49.6 \pm 7.2$ & $38.8 \pm 9.2$ \\
\hline Paired t-test & $\mathrm{T}_{1}$ 15.82. $\mathrm{p}=.000$ & $\mathrm{~T}_{3} 16.74, \mathrm{p}=.000$ & $\mathrm{~T}_{2} 20.84, \mathrm{p}=.000$ \\
\hline
\end{tabular}

${ }^{*} \mathrm{t}_{1}$ compare between before and after one month

${ }^{*} \mathrm{t}_{2}$ compare between before and after three month

${ }^{*} t_{3}$ compare between after one month and after three month

It is obvious from table (3) that total mean score of depression was decreased after one month of exercise performance than before and the mean score of depression continuously decreased after three months of exercise performance with a statistical differences between pre and after one month, pre and after three month and between after month and after three month $\mathrm{p}=.000$. As regard total mean score of fatigue there was also decrease in mean score after month and three month of exercise performance with a statistical significance difference before, after one month and after three month of intervention $\mathrm{p}=.000$.

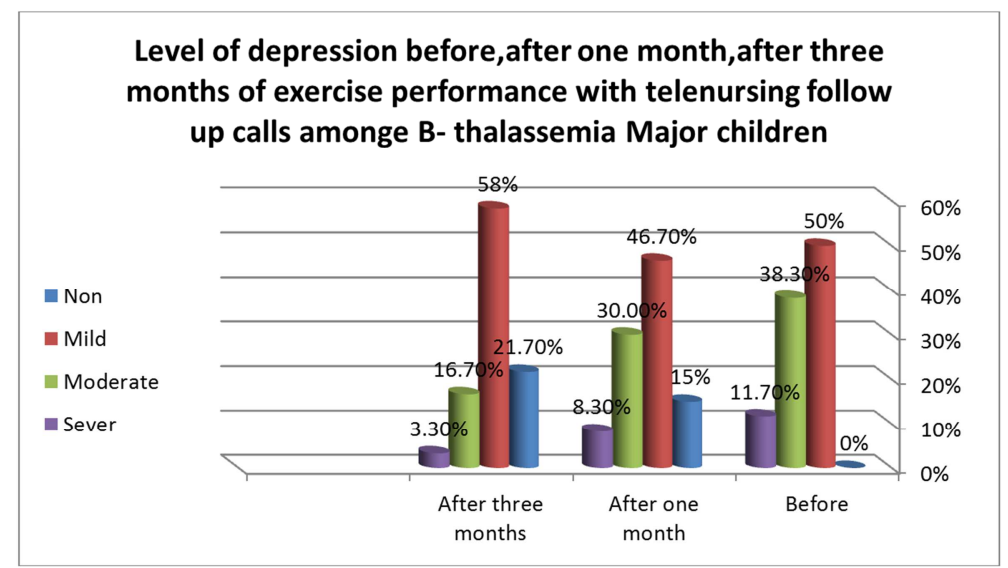

Figure 2. Shows that the level of depression among thalassemic children. Before exercise performance, all of them have depression in the form of (50\%) mild, (38.3\%) moderate and (11.7\%) sever. After one month (15\%) of children not have depression and only $8.3 \%$ had severe depression. Also after three month of exercise performance $21.7 \%$ have no depression and $3.3 \%$ have severe depression. There was a statistical significant improvement in depression level after than before exercise performance.

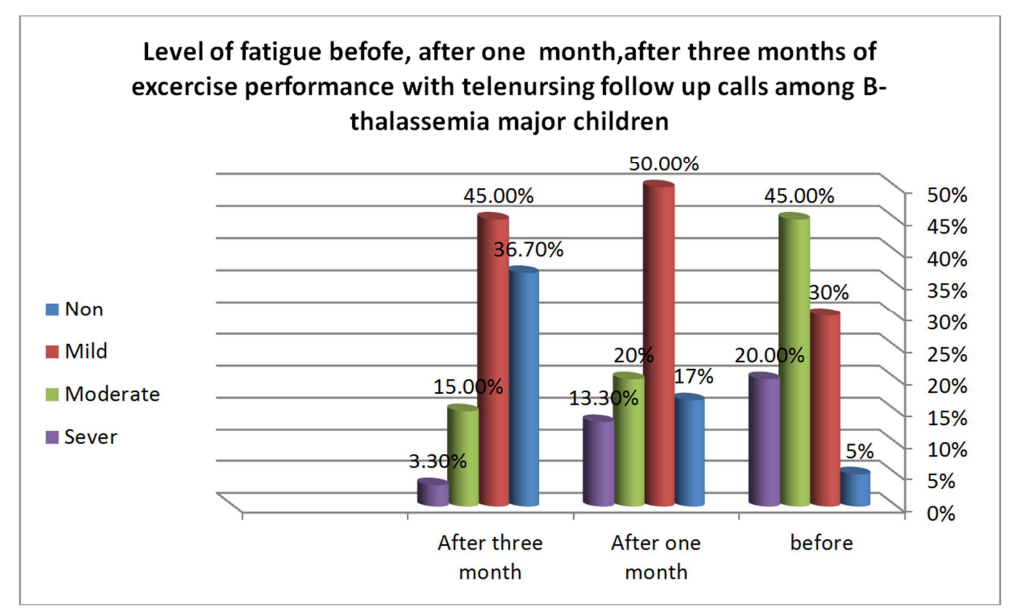

Figure 3. Shows that before exercise performance the fatigue level among thalassemic children were in the form of $30 \%$ mild, $45 \%$ moderate, $20 \%$ severe and only $5 \%$ had no fatigue, but after one month of exercise performance $17 \%$ of children had no fatigue, half of them (50\%) had mild fatigue and $13 \%$ had sever fatigue. After three month almost one third (36.7\%) had no fatigue and only $3.3 \%$ had severe fatigue. There was statistical significant differences in fatigue level before, after one month and three month of exercise performance. 


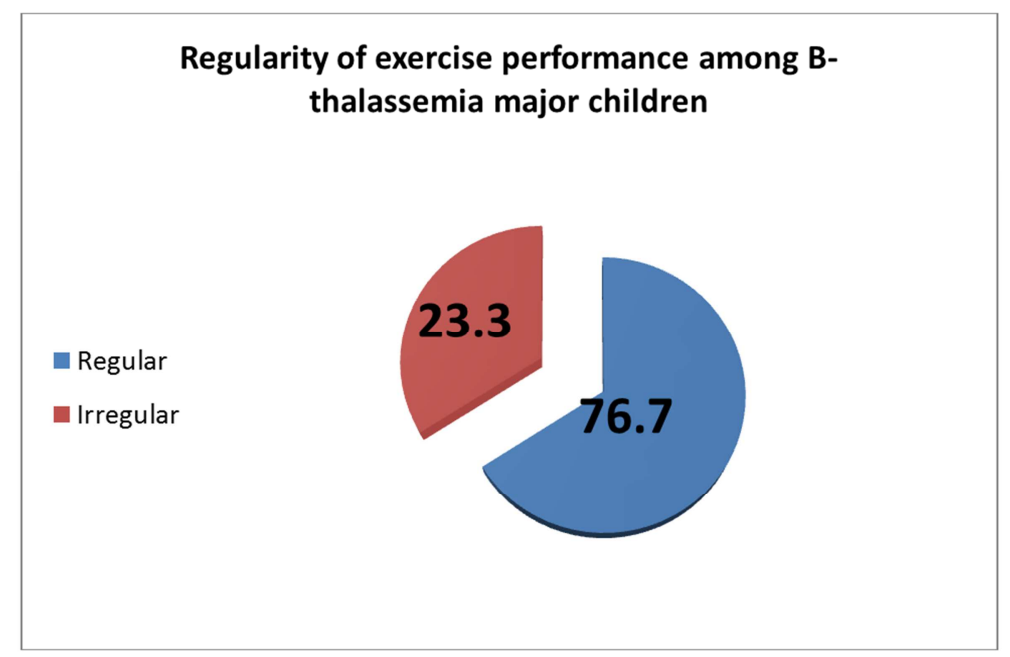

Figure 4. Shows that more two third (76.7\%) of thalassemic children were regular in performing exercise while only $23.3 \%$ were irregular in exercise performance.

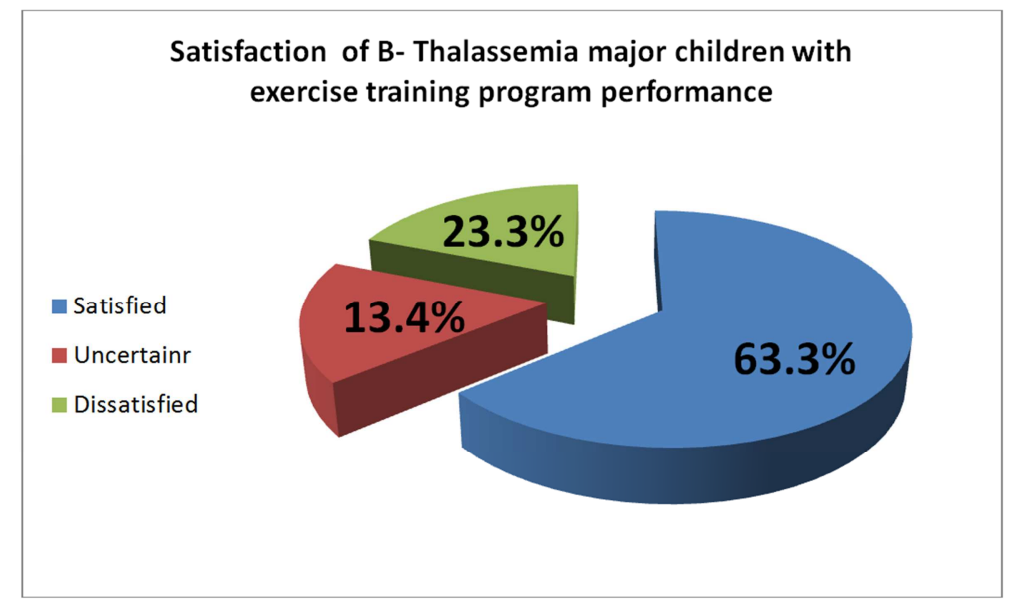

Figure 5. Satisfaction of Thalathemia children with exercise performance. It is clear from this figure that more than two third of studied children (63.3\%) were satisfied in performing exercise, $13.4 \%$ were uncertain and less than one third of children were dissatisfied.

\section{Discussion}

Children with Thalassemia major are characterized by anemia and tissue hypoxia, which are partly corrected with strict adherence to treatment based on regular transfusions in addition to chelation therapy to reduce iron load and prevents secondary hemosiderosis effects. Thalassemic children who are less active than their healthy peers generally have decreased muscle strength and flexibility that leads to feeling of fatigue as well as negative emotional sensation reached to depression from the chronic, long life nature of the disease (Wong, George and Tan 2011). Practicing exercise with follow up calls constitute a potentially promising intervention to moderate treatment side effects and have a beneficial outcomes on children's physical and emotional functions. For this reason, the current study was designed to investigate the exercise training program and telenursing effects on depression and fatigue level in children with Thalassemia major.

The results of the present study illustrated that all of studied children had depression; half of them had mild depression and the other half rang from moderate to severe depression in the basic assessment before exercise performance (figure 2). This may because most of studied children were female that become more sensitive to their body changes, and most of studied children were from rural areas and low socioeconomic status which impose financial burden required for transportation and cost of treatment, in addition to joint pain which is the common complain among children (table $1 \&$ figure 1). Hashad et al (2015) clarified that having chronic disease during childhood confers large risk of developing psychiatric disorder such as depression that impose a significant stressor with psychological and social impact on the children and their families. This results come in agreement with (Gharaibeh, Amarneh and Zamzam, 2009) who stated that the psychosocial burden on children and adolescents with Thalassemia affected by many aspects of life such as education, time off school, sport, difference from friends/siblings, social interactions, family adjustment, anxiety, isolation, and stigmatization leading to psychiatric problems mainly depression.

Practicing exercise was one of the burdens that affect 
children with thalassemia, as the disease associated with low hemoglobin levels, feeling of fatigue, and general weakness that decrease tolerance of children to perform exercise (Hockenberry and Wilson, 2013). The current study showed that an exercise program with 3 months follow up calls has a positive effect in decreasing depression score among thalassemic children after one month of exercise performance than before. In spite of feeling of tiredness and some pain during walking or movement at the beginning of exercise, the score of depression continue decreased after three months of exercise performance with a statistical significant difference before, after one month and after three month of intervention (table 2). This may due to willing and motives of children to fight against physical weakness, their regularity in taking blood and chelation therapy as well as instruction given during follow up calls to practice light exercise with short periods in the first and increased gradually according to children tolerance with emphasize on stopping exercise when feeling pain, shortens of breath or fainting. This results supported by various researches studying the effect of exercise on different chronic diseases without follow up calls; In Millagerd, Mohamadkhan and Meamarian,2002. Study that assessed the effect of regular exercise on depression in 8-12 yrs patients, the effectiveness of exercise and physical activity on depression in these clients was demonstrated. Other researches such as Milani et al (2011) in USA and Oeland et al (2010). in Denmark also indicate the efficacy of exercise on major depression in heart failure patients, which are consistent with the results of this study. For that, it's absolutely necessary in nurse telephone follow up call to empathize the importance of practicing exercise for alleviating depression in pediatric population.

Fatigue is a frequent symptom shared by most of thalassemic children. In the currentstudy $95 \%$ of studied children had experienced fatigue (figure $3 \&$ table 2 ). In this study, there was a significant difference between the fatigue scores before and after one month and after three month of exercise performance with 12 weeks telenursing. This may because of fatigue is a co symptoms of depression and can be alleviated with an improvement in children physical and psychological state. A study conducted by Riahi et al (2012) demonstrated significant reduction in the fatigue level after five months of leg ergometric exercises, which was in line with the findings of the current study. In study of Yurtkuran et al (2007) a significant improvement was observed in the patients' fatigue after 12 weeks of yoga exercises. Motedayen, et al (2014) \& Soliman (2015) stated that, there was a significant change in fatigue score pre and post eight week of the exercise program within the experimental group, as well as between experimental and control group where $\mathrm{p}$ $<.05$ that was as a result of range of motion exercises for 8 week.

Regularity of practicing exercise is an important part in treating psychological problems including depression among thalassemic children. Adherence to exercise depends on children motivation and attractive variation in physical activities offered suitable to each child (Thavorncharoensap et al,2010). The present study revealed that more than two third of studied children were regular in practicing exercise and the minority were irregular (figure 4). It looks that the telenursing intervention was effective for exercise adherence because children enjoyed the training program, which motivated them and offer the necessary variation to enhance adherence to it. While other thalassemic children who were irregular in exercise performance was probably because the effects of anemia and tissue hypoxia resulting in fatigue sensation during physical activity performance or from the associated side effects of treatment. A study was carried out to assess the quality of life of school age thalassemic children, indicated that there were a significant association between physical health status and regularity of blood transfusion per month as well as iron chelation therapy (El Dakhakhny et al, 2011). Additional support finding revealed that there were a significant association between physical function of those children family history of Thalassemia as well as with number of blood transfusion per month (Al Ebrahimy, Al jebory and Jehad, 2015).

The findings prompt that exercise training program along with twelve week telenursing follow up call associated with satisfaction in more than two third of studied thalassemic children (Figure 5). This may because applying telenursing intervention give children and their parents time to speak about the exercise program and listen attentively to their concerns which is a predictor of satisfaction as well as emotional wellbeing. The criteria for proper exercise in viewpoint of Ribeiro et al (2013) include patient's compliance, feeling comfort with program, attention to social and familial factors, and life style. This results in accordance with Bagheriyan et al (2012) who stated that children with thalassemia who experienced fewer symptoms of depression will affect on the process of adjustment and coping. Also, (Rezaei et al, 2015) believed that the efficacy of exercise program in his study can be due to strengthening muscle power, improving joints flexibility, reducing musculoskeletal pain, enhancing appetite, feeling improvement, independence and reducing fatigue sensation for patients. Also, the current findings represent the minority of studied children were uncertain and dissatisfied as regard exercise program performance, this may due to children become more emotionally sensitive toward their future life, treatment costs, their body image in comparison with their peers and fear of death.

\section{Conclusion}

The study highlighted the high prevalence of depression and fatigue among thalassemic children as all studied children suffer from depression and $95 \%$ of them suffer from fatigue with different categories. The exercise training program combined with telenursing follow up calls for 3 months was effective in decreasing depression and fatigue among thalassemic children. As well as two third of studied children was satisfied with performing exercise program. 


\section{Recommendation}

It is recommended that; performing regular suitable exercises as routine care for thalassemic pediatric population. Applying telenursing intervention to facilitate contact of pediatric patients with their physicians and nurses whenever they need. As well as special psychosocial workers for thalassemic children to alleviate any tension or pressure associated with treatment.

\section{Acknowledgment}

The author gratefully thank dr. Ehab Mansour, assistant professor, faculty of physical education, health science department for his effort and assistance in planning the exercise program suitable for studied children. Also authors appreciate children and their parent's cooperation and their acceptance to participate in the study.

\section{References}

[1] Shawky M. R and Kamal M. T. Thalassemia intermedia: An overview. The Egyptian Journal of Medical Human Genetics. 2012; 13, 245-255.

[2] El-Shanshory MR, HagagAA, Shebl SS, Badria IM, Abd ElhameedAH, Abd El-Bar ES, Al-Tonbary Y, Mansour A, Hassab H, Hamdy M, Alfy M, Sherief L and Sharaf E. Spectrum of Beta Globein Gene Mutations in Egyptian children with B-Thalassemia. Mediterranean Journal of Heamatology andInfectious diseases. 2014;6(1).

[3] Kargar Najafi M, Borhani F, Dortaj Rabari E, Sabzevari S. The Effect of Family-Centered Empowerment Model on the Motherse $^{\text {Ke }}$ Kowledge and Attitudes about Thalassemia Disorder. Iranian $\mathrm{J}$ of Pediatric Hematology and Oncology 2011; 1(3):98-103.

[4] Al Ebrahimy A. A, Al Jebory H. K and Jehad K. S. Physical Aspects of School Age Children with Thalassemia Major in AlNajaf Al-Ashraf. Medical Journal of Babylon. 2015; 12(4), $1053-1061$

[5] Koutelekos J and Haliasos N. Depression and Thalassemia in children, adolescents and adults. Health Science Journal.2013;7 (3).

[6] Bould H, Collin SM, Lewis G, Rimes K and Crawley E. Depression in paediatric chronic fatigue syndrome. Arch Dis Child 2013; 98: 425-428.

[7] Bakr, A., Amr, M., Sarhan, A., Hammad, A., Ragab, M., and ElRefaey A. Psychiatric disorders in children with chronic renal failure. Pediatr Nephrol. 2007; 22(1), 128-31.

[8] Hashad E. R, Abusaad E. F, El Naggar A. E and AbdEl-Aziz A. M. The Effectiveness of Using Children Apperception test (CAT) in Assessing Depression among Children with Chronic Renal Failure. Mansoura nursing journal. 2015.

[9] Nunes MDR, Silva MCM, Rocha EL, Lima RAG, Nascimento LC. Measurement of fatigue in children and adolescents with cancer. Text Context Nursing, Florianópolis, 2014; 23(2): 492501.
[10] Mohamed A. S. The Effectiveness of an Educational Intervention on Fatigue in Hemodialysis Patients: A Randomized Controlled Trial. IOSR Journal of Nursing and Health Science. 2014; 3, (4).

[11] Sohn Y, E, Kato R, Noetzli J. L, Gera A, Coates T, Harmatz P, Keens K. G and Wood C. J. Exercise performance in thalassemia major: correlation with cardiac iron burden.. 2012 Wiley Periodicals, Inc. American Journal of Hematology.

[12] Marinov BI, Terziyski KV, Sapunarova KG, et al. Exercise performance in children with severe beta-thalassemia before and after transfusion. Folia Med (Plovdiv) 2008; 50: 48-54.

[13] Brussel M, Lelieveld O. M, Endelbert R. H, Helders M and Takken T. Aerobic and Anaerobic Exercise Capacity in Children With Juvenile Idiopathic Arthritis. Arthritis \& Rheumatism (Arthritis Care \& Research). 2007. 57 (6): 891-897.

[14] Rezaei J, Abdi A, Rezaei M, Heydarnezhadian J and Jalali R. Effect of Regular Exercise Program on Depression in Hemodialysis Patients. International Scholarly Research Notices. 2015.

[15] Health Resources and Services Administration. What is telehealth? Available from: http://www.hrsa.gov/telehealth. [Last accessed on 2007].

[16] Hockenberry, M. J., and Wilson, D. Wong's Essentials of Pediatric nursing. 2013; 8 th ed., Mosby, Elsevier, Canada, pp, 969-971.

[17] Wagner D, Bear M: Patient satisfaction with nursing care: a concept analysis within a nursing framework. J Adv Nurs. 2009; 65(3): 692-701.

[18] Gischler SJ, Mazer P, Poley MJ, Tibboel D, van Dijk M: Telephone helpline for parents of children with congenital anomalies. J Adv Nurs. 2008; (6): 625-631.

[19] Letourneau MA, MacGregor DL, Dick PT, McCabe EJ, Allen AJ, Chan VW, MacMillan LJ, Golomb MR: Use of a telephone nursing line in a pediatric neurology clinic: one approach to the shortage of subspecialists. Pediatrics.2003; 112(5): 1083-1087.

[20] Ghazanfari Z, Arab M, Forouzi M andPouraboli B. Knowledge level and educational needs of thalassemic children's parents in Kerman. Iranian Journal of Critical Care Nursing. 2010; 3 (3): 99103.

[21] Elalfy S. M, Farid N. M, Labib H. J and RezkAllah K. H. Quality of life of Egyptian thalassemia major children and adolescents. The Egyptian Society of Haematolog. 2014.

[22] El-Gilany, A. El-Wehady, A. and El- Wasify, M. Updating and validating of the socioeconomic status scale for health research in Egypt. Eastern Miditerranean Health journal. 2012; (18) 9.

[23] Kovacs, M. 1985: The children's depression inventory (CDI). Psychopharmacol. Bull. 21, PP: 995-998.

[24] Garieb Abd-El Fattah Garieb. Arabic version of children's depression inventory. Psychological Departement, Faculty of education, Al- Azhar university. 2012. Available at El-Angluo Liberary, Egypt.

[25] Hinds PS, Hockenberry M, Tong X, Rai SN, Gattuso JS, McCartthy K, et al. Validity and reliability of a new instrument to measure cancer-related fatigue in adolescents. $\mathrm{J}$ Pain Symptom Manag. 2007; 34(6): 607-18.

[26] Cox CL: A model of health behavior to guide studies of childhood cancer survivors. Oncol Nurs Forum 2003, 30(5): 92-99. 
[27] Moscato SR, Valanis B, Gullion CM, Tanner C, Shapiro SE, Izumi S: Predictors of patient satisfaction with telephone nursing services. Clin Nurs Res 2007, 16(2): 119-137.

[28] Wahlberg AC, Cedersund E, Wredling R: Telephone nurses' experience ofproblems with telephone advice in Sweden. J Clin Nurs 2002, 12(1): 37-45.

[29] Beaulieu R, Humphreys J: Evaluation of a telephone advice nurse in anursing faculty managed pediatric community clinic. J Pediatr Health Care.2008; 22(3): 175-181.

[30] Wong DL, George E and Tan MA. A holistic approach to education program in thalassemia population: Consideration of perspectives, attitudes and perceived needs. J. Community Genet. 2011; 2(2): 71-79.

[31] Gharaibeh H, Amarneh B and Zamzam S. The psychological burden of patients with beta Thalassemia major in Syria. Pediatrics international. 2009; 51: 630-636.

[32] Millagerd H. Li, Mohamadkhan K. S, and Meamarian R. Assessment of regular exercise effect on heamodialysis children 8-12 yrs old in children medicine of Tehran, Daneshvar Journal.2002;40: 28-23.

[33] Milani R. V, Lavie C. J, Mehra M. R and Ventura H. O. Impact of exercise training and depression on survival in heart failure due to coronary heart disease. The American Journal of Cardiology.2011; 107(1); 64-68.

[34] Oeland M, Laessoe U, Olesen A. V and Munk-Jørgensen P. Impact of exercise on patients with depression and anxiety. Nordic Journal of Psychiatry. 2010; 64(3): 210-217.

[35] Riahi Z, Esfarjani F, Marandi SM, et al. The effect of intradialytic exercise training on the quality of life and fatigue in heamodialysis patients. J Res Rehabil Sci. 2012; 8(2): 21927.
[36] Yurtkuran M, Alp A, Yurtkuran M, Dilek K. A modified yogabased exercise program in heamodialysis patients: a randomized controlled study. Complement TherMed. 2007;15(3):164-71.

[37] Motedayen Z, Nehrir B, Tayebi A, Ebadi A and Einollahi B. The effect of the physical and mental exercise during heamodialysis on fatigue: A contolled clinical trial. Nephro Urol Mon. 2014; 6(4).

[38] Soliman M. H. Effect of intradialytic exercise on fatigue, electrolytes level and blood pressure in heamodialysis patient's: A randomized controlled trial. Journal of nursing education and practice. $2015 ; 5(11)$.

[39] Thavorncharoensap M, Torcharus K, Nuchrayoon I, Riewpaiboon A, Indaratna K and Ubol B. Factors affecting health -related quality of life in Thai children with Thalassemia. BMC Blood Disorders. 2010, 10:1 http://www.biomedcentral.com/1471-2326/10/1

[40] El Dakhakhny, A.; Hesham, M.; Mohamed, S.; Mohammad, F.: Quality of Life of School Age Thalassemic Children at Zagazig City, Journal of American Science. 2011; 7(1): 186191.

[41] Ribeiro R, Coutinho G. L, Iuras A, et al. Effect of resistance exercise intradialytic in renal patients chronic in heamodialysis. Jornal Brasileiro de Nefrologia. 2013; 35, (1) : 13-19.

[42] Bagheriyan S, Borhani F, Abbaszade A and Tehrani H. Nonpharmacological Interventions for Needle-related Procedural Anxiety in Children with Thalassemia. Iranian journal of blood and cancer. 2012; 5 (4). 